\title{
APPLE TREE MODEL OF EMOTION-INVOLVED PROCESSING: VIDEOS FOR EMOTIONS AND FOREIGN LANGUAGE LEARNING
}

\author{
JANA KAMENICKÁ \\ Department of Language Pedagogy and Intercultural Studies, \\ Faculty of Education, Constantine the Philosopher University in Nitra \\ Dražovská 4, 94974 Nitra, Slovakia \\ E-mail address: janey.kamenicka@gmail.com \\ ORCID: https://orcid.org/0000-0001-8903-1943
}

\begin{abstract}
Aim. The primary aim of this paper is to present and discuss the Apple-Tree Model of Emotion-Involved Processing in the context of foreign language learning with regard to didactic, neuroscientific, and psychological viewpoints. The proposed model mirrors theories which emphasize the role of emotional experiencing in the process of learning and relate it to the enhancement of cognitive processes. The secondary aim of this paper is to propose examples of application of these theories and recent research findings - with the use of videos in foreign language learning both inside and outside of the classes.

Methods. Along with several others, two studies (an action research and experiment), dealing with the role of emotional engagement and positive emotional stimuli, are discussed in more detail. Concerning the action research (Kamenická \& Kováčiková, 2019), the subjects of this study were 31 non-native teenage secondary grammar school EFL learners (i.e., 17-18 years old). In this study, the role of emotional engagement in foreign language learning was observed - with regard to learners of various learning styles. Concerning the experiment (Král'ová, Kamenická, \& Tirpáková, submitted for publication), it provided both quantitative and qualitative data. Its subjects were 82 non-native first-year university EFL students (i.e., 18-19 years old). The effect of application of positive emotional stimuli during the foreign language classes was observed - with regard to research participants' vocabulary retention, emotional experiencing, and their autonomic stress response. The qualitative data gathered dealt with research participants' subjective perception of emotionally competent stimuli applied, vocabulary recall, and experimental classes as such.

Results. The analysis of the qualitative data suggests that emotional engagement leads to better motivation to learn among learners, including the reluctant ones. Moreover, the research outcomes suggest that emotionally competent stimuli might be considered as a universal key, when it comes to engagement of learners of various learning styles. Furthermore, the qualitative data analysis also indicates that learners especially appreciate learning the foreign language through topics which are not usually part of school curriculum. The statistical data analysis indicates that positive emotional expe-
\end{abstract}


riences lead to the increase of both foreign language enjoyment and learners' foreign language vocabulary retention.

Conclusions. The research findings suggest that positive emotional stimulation of FL learners might lead to their increased motivation for learning as well as to better retention of new language items. Furthermore, they also confirm the significant role of the teacher in terms of regulation and responsibility for the learning atmosphere. As nowadays, the FL learning does not take place in classes only, the teachers' managerial guidance and direction of learners becomes essential more than ever. With regard to these findings, several ideas how to guide learners' FL learning both inside and outside of class, are proposed - with the use of videos, which are staggeringly omnipresent in everyday lives of nowadays' society.

Key words: emotions, emotion-involved processing, foreign language enjoyment, language pedagogy, neuroscience, psychology, TEFL, videos

\section{INTRODUCTION}

1 When gardeners garden, it is not just plants that grow, but the gardeners themselves" (K. Druse). The art of gardening is not about the number of plants in the garden, but rather about the beauty of the garden and the quality of the harvest. However, only to look at the harvest and judge its quality would be very shallow. With regard to high-quality harvest, the secret is in care, which can be provided by nature itself or by the gardener. When it comes to foreign language education, it can be said that care and the harvest are equally important. However, the care is often overlooked as educators or learners too often concentrate on the harvest only. Even if the plants' basic needs are ensured, to help them flourish and grow, the gardener needs to provide them with some additional nutrition. Similarly, in education, to help the learners grow and to support their cognitive processes, the educator should provide additional nutrition in the form of emotions.

Nowadays, numerous platforms provide foreign language teachers with unlimited options to bring in emotions and authentic language to their classes. What is more, it is possible for teachers to take foreign language learning out of the class, and make it an addictive everyday hobby for their learners.

\section{EMOTIONS IN EDUCATION}

The importance of emotion in life has been widely recognized by philosophers, scientists, and educators all around the world. Traditional understanding of cognition and its prioritizing over emotions has been overcome by philosophers such as Alfred North Whitehead, Henri Bergson, Charles Sanders Peirce, William James, and John Dewey (Kanazawa, 2019b). Researchers from several scientific fields, such as developmental psychology, educational psychology, behavioral economics, neurology, sociobiology, cognitive science, neurobiology, psychopathology, physics, etc., recognize the important role of emotions in cognitive processes (Kanazawa, 2019c). No longer are emotion 
and cognition considered as two separate entities. It is believed that emotions can and often do go hand in hand with cognition as they have the potential to energize and regulate cognitive processing rather than to distract it (Storbeck \& Clore, 2007).

The developments in the field of positive psychology in the 2000s has led researchers to more detailed study of the affective areas in education and the role of emotions in foreign language pedagogy, applied linguistics, and educational psychology. The concept of emotion has become widely discussed by researchers (Dewaele, 2011; Pavlenko, 2013; Sharwood Smith \& Truscott, 2014; Swain, 2013; White, 2018). Terms such as emotional intelligence (Dewaele, Petrides, \& Furnham, 2008); Kanazawa, 2019d; Salovey \& Mayer, 1990), flow as an optimal experience (Dörnyei, Henry, \& Muir, 2016; Csikszentmihalyi, 1990), and positive psychology as the scientific study which focuses on human flourishing and strengths of human psyche (Kanazawa, 2019a; Oxford, 2016; Seligman \& Csikszentmihalyi, 2000), has come forward. As a result, several researchers tried to verify the effects of emotions on cognition in terms of foreign language (FL) learning, or more precisely, vocabulary acquisition (Dewaele \& Pavlenko, 2002; Král'ová, Kamenická, \& Tirpáková, submitted for publication; Schütze, 2017).

An interesting neuroscientific phenomenon - from which both foreign language learners and teachers can benefit - is the so-called emotionally competent stimulus (ECS). Carmine Gallo (2014) explains that when experiencing these stimuli, we enter a heightened state of emotion, which will result in better likelihood of remembering delivered messages. In fact, these stimuli trigger emotional arousal and thus create memories in which not just events but also accompanying emotional sensations are involved, remembered, and later recalled. According to John Medina (2008), ECS is the best-processed kind of external stimulus ever measured. When compared to emotionally neutral memories, ECS persist longer in the human memory. Subsequently, they are recalled with greater accuracy than the neutral ones. This phenomenon comes under such names as emotionally-enhanced memory (Talmi, Schimmack, Paterson, \& Moscovitch, 2007) or affective input enhancement (Truscott, 2015). Gallo (2014) refers to this phenomenon as emotionally enhanced vividness, an emotionally charged event, and flashbulb memory. Rebecca Todd (2014) confirms that emotionally arousing things are perceived by the human brain with greater clarity than the ordinary ones. As a result, it can be concluded that the recall of an event is influenced by the vividness of the experience in the first place.

In the field of foreign language learning, an experimental study conducted by Pilar Ferré (2003) indicated that the emotionality of lexical items and how the items are processed has a different impact on subsequent vocabulary learning. The outcomes of this study indicated that lexical valence is an important factor when it comes to FL vocabulary learning. The outcomes of the aforementioned experiment are in concordance with similar studies on foreign language vocabulary memory, which were conducted later by Ayşe Ayçiçeği 
and Catherine Harris $(2004 ; 2009)$. A recent study conducted by Yu Kanazawa (2016) experimentally investigated the impact of vocabulary items of different lexical valence on incidental recall lexical retention. The research has shown that positively valenced words were learned better - when compared to negative words, the difference was significant; in comparison to neutral words, the difference was marginal. To add, Kanazawa (2020) proposed an interesting hypothesis, that emotion-involved processing is an even deeper level of processing than semantic processing or perceptual processing - which, as a result, leads to better long-term retention. The aforementioned hypothesis is schematically displayed in the following figure:

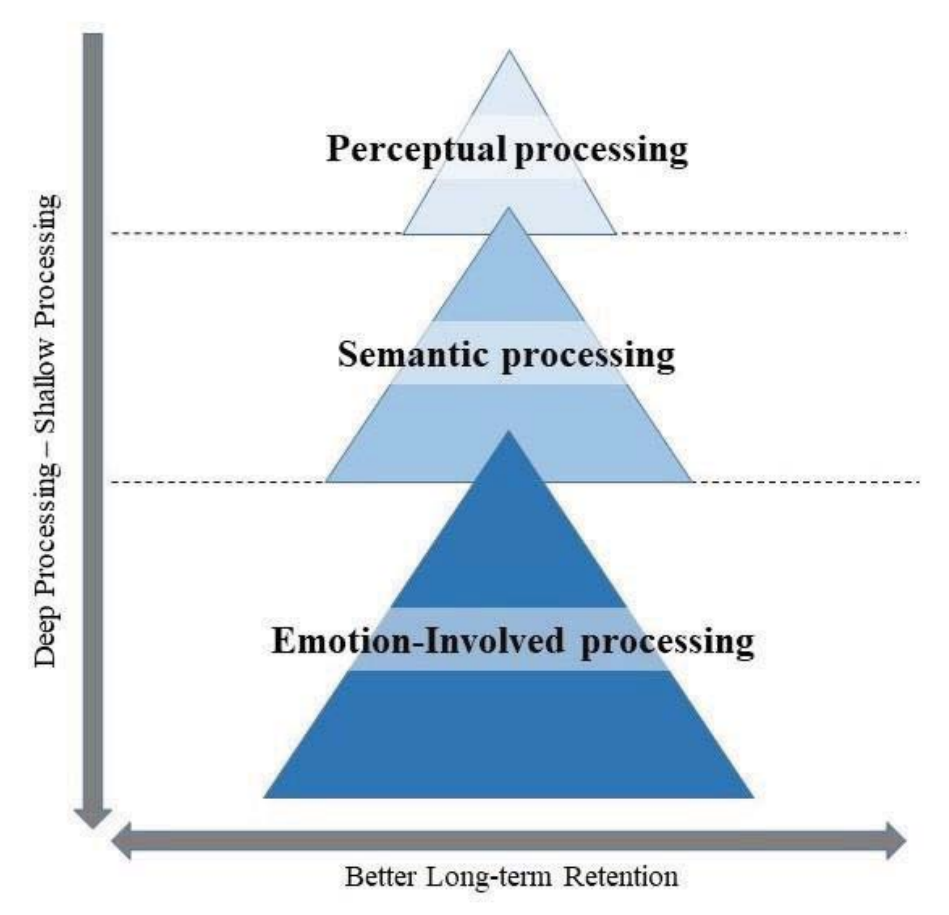

Fig. 1. Emotion-Involved Processing Hypothesis (EIPH).

Source: adapted from Kanazawa (2020)

Although the significance of lexical valence in emotion-involved processing is undisputable, this theory is bound to specific lexical items. However, in order to affect the whole group of learners in educational practice, something of more universal nature is needed. Although emotional experiencing is a very subjective phenomenon, the action research conducted by Jana Kamenická and Elena Kováčiková (2019) on 31 non-native teenage secondary grammar school EFL learners (i.e., 17-18 years old), suggests that an added positive emotional input/stimulation and consequent emotional engagement might positively 
affect foreign language acquisition. In the following study of mixed qualitative-quantitative methods approach, which was conducted by Zdena Králová, Jana Kamenická and Anna Tirpáková (submitted for publication), the effect of emotionally competent stimuli (ECS) (as the intervention), which were often delivered through videos, was observed - with regard to research participants' retention of vocabulary, emotions experienced, and their autonomic stress responses. The subjects were 82 non-native first-year university EFL students (i.e., 18-19 years old). The qualitative data gathered dealt with research participants' subjective perception of emotionally competent stimuli applied, vocabulary recall, and experimental classes as such.

In the above mentioned research, the ECS of various forms were implemented during the regular English (EFL) classes. Vocabulary test and speaking test were applied to detect the retention of the declarative and procedural knowledge of the target vocabulary items. The second objective of the mentioned study was to monitor the emotional status of the participants during the intervention. In order to measure participants' general emotional state, the Emotional Habitual Subjective Comfort Scale (EHCS) (Džuka \& Dalbert, 2002) was used. Moreover, the Foreign Language Enjoyment Scale (FLES) (Dewaele \& MacIntyre, 2014) was used to reflect their specific emotional states related to FL learning before and after the intervention. In addition, to detect the autonomic stress response, the participants' heart rate was measured during the speaking test. After the intervention, the learners were asked to fill in the feedback questionnaire in order to learn their ideas, perceptions, and reflections on the learning process.

When it comes to the vocabulary test, the improvement of the experimental group after the intervention in the post-test was more than double - in comparison with the control group. Concerning the speaking test, the post-test improvement was a little higher in the experimental group, although the improvement was not statistically significant. To conclude, the results of this experiment suggest that ECS affect declarative vocabulary knowledge more than the procedural one. Regarding the general emotional states of participants, the EHCS pre-test - post-test differences were not statistically significant. However, when it comes to FLES, the foreign language enjoyment increased in both groups after the intervention, but the increase was more than twice as high in the experimental group. With regard to autonomic stress responses, the heart rate measurement did not show any statistically significant differences, when it comes to the stress release during the post-test. The feedback questionnaires revealed that the participants in the experimental group perceived the ECS as their favorite part of the EFL class and claimed they would appreciate more of them in the future. Furthermore, they claimed that the ECS had helped them remember new vocabulary mainly because they were fun, multi-sensory and dealt with topics which are not usually included in the school curriculum. Thus, the authors of this experiment imply that ECS in foreign language education is an easily applicable strategy, which is transferable across various cultural and language contexts. At the same time, they emphasize the responsibility 
of the teacher for the regulation of the learning atmosphere in the classroom (Horwitz, 1986).

In accordance with the aforementioned pedagogical, neuroscientific, and psychological research done in this field, we propose the Apple Tree Model of Emotion-Involved Processing:

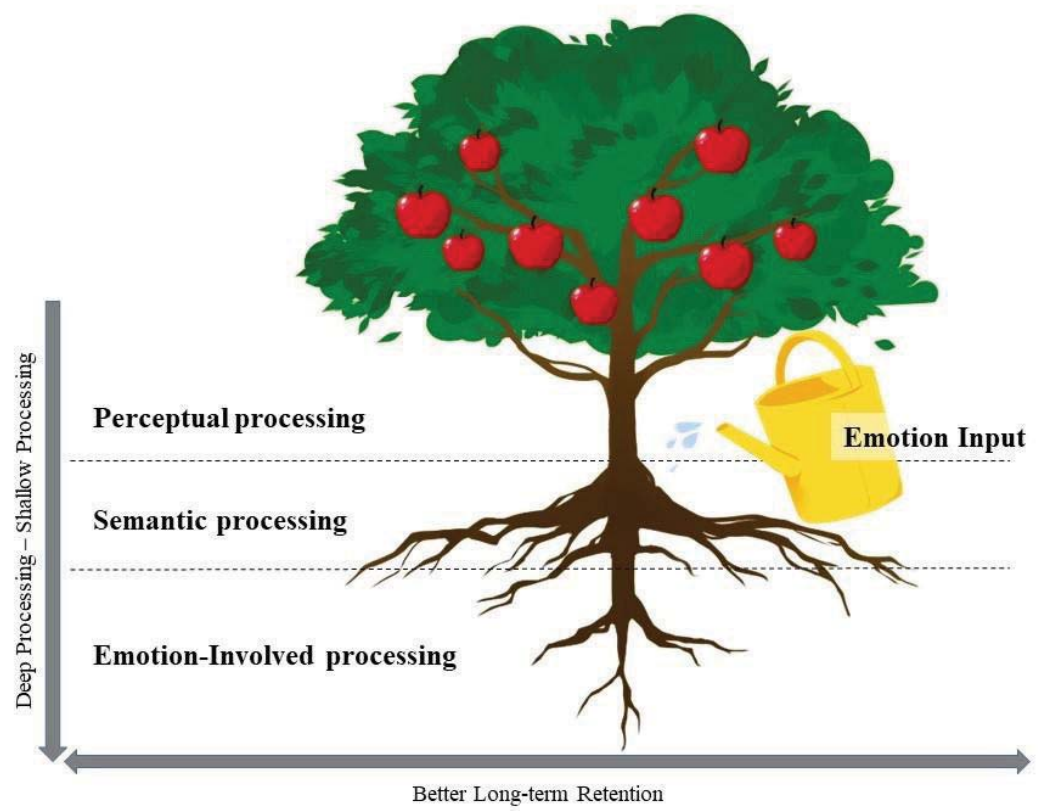

Fig. 2. Apple Tree Model of Emotion-Involved Processing.

Source: own research

To explain this figure, in order to help the tree to grow, we have to provide it with sufficient care. Every single part of the tree is equally important, the trunk and branches (perceptual processing), the shallow root system (semantic processing), and the deepest roots (emotion-involved processing). However, for the tree to survive, water and nourishment (emotions) are essential. These can be provided by nature itself, but only a caring gardener (the teacher) can provide the tree with the best care it needs to bear the highest-quality fruits. It is the water and the nourishment contained in the gardener's watering can (emotional input, i.e. tasks during which ECS are experienced) that reaches and nourishes the deepest roots of the tree, and subsequently, supports the foundations and the tree itself. Therefore, the emotional experience supports the "foundations" of learners, and at the same time, provides their teachers with great opportunity to give a form to their "shapes". As a result, the tree will bear fruits. Again, to bear delicious and juicy apples, the tree needs appropriate nourishment and water - to ensure the best possible outcome (a rich 
harvest), they are provided and/or supplemented by the gardener himself/ herself. Thus, the emotional input provided by the teacher has the power to support learners' psychological foundation, and at same time, helps to ensure the cognitive harvest.

\section{VIDEOS FOR FOREIGN LANGUAGE LEARNING}

First, in order to understand the potential of videos in education, it is essential to understand their nature. Claiming that they are just "moving pictures" would be an inadequate and insufficient definition, as they comprise pictures, sounds and music, and some sort of movement or dynamic (which is often achieved through storytelling). As proposed by Gallo (2014), to enhance learning, the following brain-friendly tools and aids can be used:

- pictures, images, and videos,

- props and demos,

- memorable headlines,

- unexpected and shocking statistics,

- personal stories.

In education, most of the aforementioned can be achieved through videos. Therefore, when using videos in foreign language (FL) education, learners do not learn just the linguistic content - they are also given an opportunity to learn about something beyond it. Videos provide FL learners with a space for learning languages - while often providing them with first-hand and real-life experiences, and an authentic language environment. What is more, learners can and often do identify with characters in the video, especially if they have something in common.

With regard to various learning styles, Jim Scrivener (2011) distinguishes three types: visual, auditory, and kinesthetic (VAK learning styles). Concerning the first group of learners, visual, they learn best by seeing - e.g., graphics, pictures, illustrations demonstrations, lists, etc. The next group mentioned benefits from auditory input, such as spoken presentations, songs, jazz chants, rhythm and sounds as memory aids, out loud drilling, spoken storytelling, and spoken interviews. The last group benefits from dynamic sensations, which include movement - for instance, TPR activities, motion games, miming, using props, making products, experiments, movements as memory aids - especially when learning or revising. According to further research findings (Kamenická \& Kováčiková, 2019), pictures, music and sounds, and kinesthetic dynamics, are the three aspects, which indicate, that videos in education, especially FL education, might be considered as a universal key to use, when dealing with the grammar school learners of VAK learning styles. Regarding the aforementioned study, using videos as carriers of real life stories, storytelling was implemented to increase FL enjoyment and engagement of learners - in order to enhance their FL vocabulary learning. Most of them, including the reluctant learners, claimed they benefited 
from the implemented activities. The participants of this research also claimed that the videos complemented a context of the new vocabulary input, which was often missing in the textbooks and added authenticity to the FL classes. In addition, they enabled the participants to learn about cultural and historical aspects of society, not just the language input itself. The results of this action research also suggest that a certain dynamic, or rather a sense of movement, which is needed for kinesthetic learners, might be delivered through videos and Prezi presentations - which, at the same time, are advantageous to learners of visual and auditory learning styles.

Bearing in mind all the feedback from the aforementioned action research participants, we propose that when learning a foreign language, the "3 reals" principle" should be applied: students should be learning about real life, using real language in real contexts (Kamenická, 2019). In the context of education, it is believed that doing authentic and real-world tasks motivates students to learn (Greenspan \& Benderly, 1997). Furthermore, motivation has often been discussed with emotional sensations (Frick, 2015). Therefore, when it comes to triggering emotional responses and enhancement of FL learning, it is essential to emphasize the importance of authentic language input, which can be provided by stories, jokes, videos, etc., and subsequent performance of related authentic tasks.

Concerning the motivation to learn, Robert C. Gardner (2010) created the so-called socio-educational model of motivation. The author proposes that when it comes to FL learning, it is learners' positive attitudes towards the teacher, foreign language course, and target language which play the prominent role. Similarly, several other researchers (Dewaele, Witney, Saito, \& Dewaele, 2017) emphasize the importance of the teacher, when it comes to their learners' motivation. According to this study, foreign language enjoyment (FLE) is related to the FL teachers' practices, while foreign language anxiety (FLA) seems less related to them. Therefore, it is suggested to concentrate on boosting the FLE, rather than worrying too much about FLA. As proposed in the aforementioned study, the role of the teacher is central not only when it comes to the production of comprehensible discourse, but also when it comes to the creation of an appropriate learning environment. In such environment, "students believe in the value of learning a language, where they feel they can face that challenge and where they understand the benefit they can get from attaining it" (Arnold \& Fonseca, 2007, p. 119) which can be achieved both through verbal and non-verbal means, including the use of videos as a part of education. Another study, which was conducted by Nasrah M. Ismail (2016), verified the effect of the engagement program on alleviation of FLA and enhancement of motivation of female university students of English to learn, which included several learning activities, in which educational videos played an important role, too. 


\section{ROLE OF EDUCATORS}

As we already suggested, to enhance FL learning, teachers should strive for their learners to have positive emotional experiences during the process of learning. Every teacher can be likened to a seller of a product. Their goal should be to persuade the buyer that they need the product and will use it in the future - and possibly, persuade their friends to buy it, too. When it comes to business, it is often a video which sells the product.

As discussed, videos comprise pictures, music and sounds, and certain dynamics. Although all of these are important in a video, the music can affect the viewer in a very significant way. Every teacher can verify its effect during the educational process in a very simple experiment. For this experiment, a footage of a battle can be used. If you add a soundtrack composed in a minor key, the viewers will perceive the video from the side of the defeated army. Subsequently, you can play them the same footage, however, this time with a soundtrack composed in a major key. The viewers will perceive the video from the side of the victorious army. Although the footage is the same, it is the music that makes the difference and provides the educator with the possibility to multiply or manipulate the emotional experience the viewers get. Several researchers dealt with the influence of music on the meaning (Boltz, 2004; Boltz, Scholkind, \& Kantra, 1991; Shevy, 2007; Tan, Spackman, \& Wakefield, 2017) and agreed on the fact that the power of music in movies is remarkable in this regard - whether it precedes, foreshadows, accompanies, or follows a certain event. When it comes to education, to multiply the emotional experience from a video, videos with interesting music can be used.

When sufficiently emotionally engaged, the learners become the teachers' regular "clients". However, it is not only "selling of a product", which is the main role of teachers. The teachers should become leaders and managers with whom other people, including their students, want to work. Together they work on collaborative projects - so that all of them profit and spread "the product" far and wide.

\section{VIDEOS IN USE}

As we discussed, the potential of videos to stimulate emotional experiencing in learners, is rather interesting. However, it is essential to emphasize that watching videos is more of a perception than of language production. However, in FL education, a receptive input should be followed by a productive output. How? After watching a video, several activities can be performed to elicit productive responses from learners, both spoken and written:

- description of the scene - to elicit basic vocabulary (esp. nouns and adjectives for the beginner learners of a FL),

- retelling or description of events - to practice the use of grammar (esp. various verb forms and tenses), 
- discussion - for checking learners' comprehension, for better understanding of a problem, social and cultural issues, etc.,

- comparing the video with personal experiences,

- speculating - esp. about events that preceded or might follow (to practice past and future tenses) what if-s (to practice conditionals).

Another possible use of videos in FL learning can be watching just for enjoyment - which can be followed by a genuine reaction and/or reflection of learners to the content of the video. It is important to inform the learners that they are about to watch a video just to enjoy it and that no comprehension tasks will follow. Usually, a sigh of relief can be heard in the classroom after such information - followed by the relaxing postures of the students.

To combine business with pleasure, we propose that learning a foreign language should take place not only in the classroom, but also outside of the classroom - not because the learners have to learn, but because they want to and do enjoy the experience of a foreign language. Therefore, we propose several ideas on how to choose videos which provide learners with up-to-date lexical input and fresh information every day. These ideas can be derived from and build up by the teachers themselves or they can be simply recommended to FL learners in order to improve their FL skills:

Following a foreign YouTube channel. There are thousands of YouTube channels, which deal with travelling, make-up, fashion, cooking, scale model-making, tuning cars, nature, survival in nature, primitive survival techniques, playing a musical instrument, gaming, archeology, etc. The advantage here is an unlimited source of new vocabulary in someone's field of interest. The added value is the emotion that is triggered from someone's favorite activity, hobby or dealing with a topic of their interest. Moreover, when following a YouTube channel, the learner is provided with new videos on a regular basis and when engaged, they do not want to miss them. As a result, they learn a foreign language on a regular basis - without even realizing it, as they are absorbed in following their hobby.

Watching quality foreign reality shows. There are numbers of reality shows, which deal with travelling, gold-mining, survival in nature, production of goods and devices (how things are made), weird places, mysterious history, hidden secrets, hidden places and buildings, animals, car reparations and tuning, auctions, buying wedding or prom dresses, buying flats and houses, fishing, etc. Again, these reality shows provide a non-native speaker of a foreign language with an unlimited source of new vocabulary in the area of their interest.

Watching BBC News. This gives learners an opportunity to learn about most recent events - and consequently, to constantly update their vocabulary. For English learners, the most significant benefit of $\mathrm{BBC}$ is indisputably the opportunity to come to touch with so-called RP English, which we will discuss later.

Watching movies in a foreign or the original language. This can give learners an opportunity to enjoy the movie even more than when watching it in 
a dubbed version. The fluent foreign language speakers agree that a lot can be lost in translations. Not to mention the fact that the dubbing performances of actors are not always convenient enough for every viewer. Sometimes, it is advantageous for a foreign language learner to watch a movie in a foreign language, which they are already familiar with in their mother language. This provides them with a sense of safety and alleviates their anxiety.

Watching TV series in a foreign or the original language. In the era of Netflix and HBO GO, being a regular viewer of a TV series is nothing uncommon. An exciting storyline and viewers' identifying with its characters is what has the real power to emotionally stimulate and engage. The viewers do not even realize that at the same time, they become learners. Again, the regular and gradual release of episodes, the exciting storyline, and strong characters, is what makes the TV series addictive to the learner.

Using Google Street View + YouTube videos. Choosing a random place on the map and peeking there through Google Street View brings a sense of curiosity and wonder, and allows both teachers and learners to learn about exotic places - the popular ones, or the ones they have never heard of. Subsequently, watching a YouTube video and a follow-up use of the aforementioned activities, dealing with that particular place or the issues its inhabitants have to face, provide a great opportunity for further foreign language acquisition.

A fact worth highlighting is that, when applying these ideas, the learners are exposed to FL speakers of various accents. When it comes to English, the BBC News provides FL learners with an opportunity to listen to the so-called RP English, which is a UK pronunciation variety, often seen as a standard educated pronunciation (Scrivener, 2011). However, the RP is not a rule in the rest of the mentioned video ideas. Accents and numerous varieties of English can be found in these videos and movies - which is very advantageous to learners - as in real life, it is both native and non-native speakers of English that the learners might come into contact with. Hence, the learners of a foreign language should aim to communicate effectively and intelligibly with people of various nationalities and cultures.

Another advantage of being exposed to authentic language in the mentioned videos and movies is the fact, that they provide the learners with an opportunity to improve not only vocabulary and grammar, but also those aspects of foreign language which are not usually taught at schools - the supra-segmental level of phonetics and phonology, i.e., prosodic features, such as word stress, sentence stress, tone, intonation, etc. (Král'ová, 2009; Roach, 2009) - which leads to the overall improvement of their pronunciation and thus to better intelligibility of their utterances.

\section{CONCLUSION}

Bearing in mind the apple tree model, the gardening tools provided by the pedagogical and psychological education the foreign language teachers 
acquired, might not be sufficient for their plants' well-being today. To know the plant and the conditions for its growth is equally important - and that is the role of the teacher, as the educator, to support and help them grow - so that they can flourish, blossom and/or bloom and bring harvest. Although the author and her co-workers are currently working on a more detailed empirical study, the question of how to deliver emotionally competent stimuli in the class and what materials could be used to emotionally stimulate the learners, is also for the teachers themselves and for the readers of this paper to answer, too.

Lastly, more diverse methodologies should be integrated and collaboration with other researchers in this field would be fruitful in a future study. The multidisciplinary mixed methods approach in the further research can be especially beneficial - in order to provide the educators and teachers with "fertilizers" for their gardens - particularly designed for the conditions we currently live in.

\section{ACKNOWLEDGEMENTS}

This work was supported in part by the grant KEGA 002UKF-4/2020 of the Ministry of Education, Science, Research, and Sport of the Slovak Republic, and in part by the grant UGA V/7/2020 of the Constantine the Philosopher University in Nitra, Slovak Republic.

\section{REFERENCES}

[1] Arnold, J., \& Fonseca, C. (2007). Affect in teacher talk. In: B. Tomlinson (Ed.), Language Acquisition and Development (pp. 107-121). New York: Continuum.

[2] Ayçiçeği A., \& Harris, C. L. (2004). Bilinguals' recall and recognition of emotion words. Cognition and Emotion, 18(7), 977-987.

[3] Ayçiçeği A., \& Harris, C. L. (2009). Emotion-memory effects in bilingual speakers: A levels-of-processing approach. Bilingualism: Language and Cognition, 12(3), 291-303.

[4] Boltz, M. G. (2004). The cognitive processing of film and musical soundtrack. Memory \& Cognition, 32(7), 1194-1205.

[5] Boltz, M. G., Scholkind, M., \& Kantra, S. (1991). Effects of background music on remembering of filmed events. Memory \& Cognition, 19(1), 593-606.

[6] Csikszentmihalyi, M. (1990). Flow: The psychology of optimal experience. New York: Harper \& Row.

[7] Dewaele, J.-M. (2011). Reflections on the emotional and psychological aspects of foreign language learning and use. Anglistik. International Journal of English Studies, 22, 23-42.

[8] Dewaele, J.-M., \& MacIntyre, P. D. (2014). The two faces of Janus? Anxiety and enjoyment in the foreign language classroom. Studies in Second Language Learning and Teaching, 4(2), 237-274.

[9] Dewaele, J.-M., \& Pavlenko, A. (2002). Emotion vocabulary in interlanguage. Language Learning, 52(2), 263-322.

[10] Dewaele, J.-M., Petrides, K. V, \& Furnham, A. (2008). Effects of trait emotional intelligence and sociobiographical variables on communicative anxiety and foreign language anxiety among adult multilinguals: A review and empirical investigation. Language Learning, 58(4), 911-960.

[11] Dewaele, J.-M., Witney, J., Saito, J., \& Dewaele, L. (2017). Foreign Language Enjoyment and Anxiety in the FL Classroom: The Effect of Teacher and Learner Variables. Language Teaching Research, 22(6), 676-697. 
[12] Dörnyei, Z., Henry, A., \& Muir, C. (2016). Motivational currents in language learning: Frameworks for focused interventions. New York: Routledge.

[13] Džuka, J., \& Dalbert, C. (2002). Vývoj a overenie validity Škál emocionálnej habituálnej subjektívnej pohody (SEHP) [Elaboration and verification of emotional habitual subjective wellbeing scales (SEHP)]. Československá psychologie, 46(3), 234-250.

[14] Ferré, P. (2013). Effects of level of processing on memory for affectively valenced words. Cognition and Emotion, 17(6), 859-880.

[15] Frick, T. (2015). Emotions, Learning, and Good Teaching. Bloomington: Indiana University Bloomington.

[16] Gallo, C. (2014). Talk Like TED. New York: Macmillan.

[17] Gardner, R. C. (2010). Motivation and second language acquisition: The socio-educational model. New York: Peter Lang.

[18] Greenspan, S. I., \& Benderly, B. L. (1997). The growth of the mind and the endangered origins of intelligence. Reading: Addison-Wesley.

[19] Horwitz, E. K. (2017). On the Misreading of Horwitz, Horwitz, and Cope (1986) and the Need to Balance Anxiety Research and the Experiences of Anxious Language Learners. In: Ch. Gkonou, M. Daubney, \& J.-M. Dewaele (Eds.), New insights into language anxiety: Theory, research and educational implications (pp. 31-47). Bristol: Multilingual Matters.

[20] Ismail, N. M. (2016). The Effectiveness of an Engaging Program to Reduce Saudi Female University EFL Students' Foreign Language Anxiety and to Enhance their Motivation to Learn English at Taif University. International Journal of Psychological Studies, 8(1), 92-105.

[21] Kamenická, J. (2019). How to Enjoy the Journey: Foreign Language Vocabulary Learning and Teaching. Slavonic Pedagogical Studies Journal, 8(2), 277-295.

[22] Kamenická, J., \& Kováčiková, E. (2019). Emotional Engagement in Teaching English Vocabulary. Praha: Verbum.

[23] Kanazawa, Y. (2019a). Beyond positive psychology: Philosophical insights to avoid the potential dangers of vulgarized appreciations of positive emotion. Journal of International Studies, $8(1), 109-118$.

[24] Kanazawa, Y. (2020). Emotion as "deeper" than cognition: Theoretical underpinnings and multidisciplinary lignes de faits to the Emotion-Involved Processing Hypothesis (EIPH). Journal of International Studies, 9(1), 185-206.

[25] Kanazawa ,Y. (2019b). Emotion-cognition-body interconnected dynamism: Multidisciplinary and neuroscientific perspectives. Journal of International Studies, 8(1), pp. 97-108.

[26] Kanazawa, Y. (2019c). From the emotion/cognition dichotomy to an organic whole: Philosophical perspectives via James, Whitehead, Peirce, Dewey, and Bergson. Journal of International Studies, 8(1), 85-96.

[27] Kanazawa, Y. (2016). Micro-level emotion as a factor of L2 vocabulary memory: The effect of lexical emotional valence on incidental recall performance. Language Education $\mathcal{E}$ Technology, 53, 23-52.

[28] Kanazawa, Y. (2019d). Trait emotional intelligence as an individual difference in the effectiveness of (non)Emotion-Involved Semantic Processing: Potential interplay between macro- and micro-level emotion in foreign language vocabulary learning and acquisition. Kwansei Gakuin University Humanities Review, 24, 1-11.

[29] Král'ová, Z. (2009). Faktory anglickej fónickej kompetencie [Factors of English Phonic Competence]. Žilina: University of Žilina.

[30] Král'ová, Z., Kamenická, J., \& Tirpáková, A. Emotionally Competent Stimuli in Teaching Foreign Language Vocabulary. Submitted for publication.

[31] Medina, J. (2008). Brain Rules. Seattle: Pear Press.

[32] Oxford, R. L. (2016). Toward a psychology of well-being for language learners: The 'EMPATHICS' vision. In: P. D. MacIntyre, T. Gregersen, \& S. Mercer (Eds.), Positive psychology in SLA (pp. 10-87). Bristol: Multilingual Matters.

[33] Pavlenko, A. (2013). The affective turn in SLA. In: D. Gabryś-Barker, \& J. Bielska (Eds). The affective dimension in second language acquisition (pp. 3-28). Bristol: Multilingual Matters.

[34] Roach, P. (2009). English Phonetics and Phonology. Cambridge: Cambridge University Press.

[35] Salovey, P., \& Mayer, J. D. (1990). Emotional intelligence. Imagination, Cognition and Personality, 9(3), 185-211. 
[36] Schütze, U. (2017). Language learning and the brain: Lexical processing in second language acquisition. Cambridge: Cambridge University Press.

[37] Scrivener, J. (2011). Learning Teaching. Oxford: Macmillan Education.

[38] Seligman, M. E. P., \& Csikszentmihalyi, M. (2000). Positive psychology: An introduction. American Psychologist, 55(1), 5-14

[39] Sharwood Smith, M., \& Truscott, J. (2014). Multilingual mind: A modular processing perspective. Cambridge: Cambridge University Press.

[40] Shevy, M. (2007). The mood of rock music affects evaluation of video elements differing in valence and dominance. Psychomusicology, 19(2), 57-78.

[41] Storbeck, J., \& Clore, G. L. (2007). On the interdependence of cognition and emotion. Cognition and Emotion, 21(6), 1212-1237.

[42] Swain, M. (2013). The inseparability of cognition and emotion in second language learning. Language Teaching, 46(2), 195-207.

[43] Talmi, D., Schimmack, U., Paterson, T., \& Moscovitch, M. (2007). The role of attention and relatedness in Emotionally Enhanced Memory. Emotion, 7(1), 89-102.

[44] Tan, S. L., Spackman, M. P., \& Wakefield, E. M. (2017). The Effects of Diegetic and Nondiegetic Music on Viewer's Interpretation of a Film Scene. Music Perception, 34(5), 605-623.

[45] Todd, R. (2014). Discussion with Carmine Gallo, February 25, 2013. In: C. Gallo, Talk like TED. New York: Macmillan.

[46] Truscott, J. (2015). Consciousness and second language learning. Bristol: Multilingual Matters.

[47] White, C. J. (2018). The emotional turn in applied linguistics and TESOL. In: J. de Dios Martínez Agudo (Ed.), Emotions in second language teaching (pp. 19-34). Switzerland: Springer. 